\title{
Anomalous Changes in Austenite and Martensite Lattice Parameters of Fe-Mn-C Alloys
}

\author{
By Yasuji Tanaka* and Ken'ichi Shimizu**
}

\begin{abstract}
Austenite and martensite lattice parameters of $\mathrm{Fe}-8.7 \sim 4.1 \% \mathrm{Mn}-0.57 \sim 1.25 \% \mathrm{C}$ alloys have been measured in detail as a function of temperature, by means of X-ray diffractometer with a cooling stage. The austenite lattice parameters during martensitic transformatins are smaller than the extrapolated ones from high temperature values before the martensitic transformations occur. The amount of the reduction is nearly the same for all the alloys when the amount of martensites is less than about $50 \%$, but it becomes larger with decreasing carbon content when the amount of martensites is over $50 \%$. The $a$ parameters of martensites upon cooling decrease with decreasing temperature and/or increasing amount of martensite, and those upon heating first increase and then linearly decrease with temperature showing a critical transition point at about $160 \mathrm{~K}$. On the other hand, the $c$ parameters of martensites are nearly the same upon cooling and heating. It is also confirmed that the martensites at liquid nitrogen temperature have an anomalously small $c / a$ ratio and change to normal upon heating to room temperature. The $c$ parameters and $c / a$ ratios of martensites are changed upon ageing at room temperature. The origins of the anomalous changes in austenite and martensite lattice parameters are discussed.
\end{abstract}

(Received September 17, 1979)

\section{Introduction}

A number of studies have been made on a change in austenite lattice parameters during martensitic transformations in various ferrous alloys and carbon steels. Ridley et al. ${ }^{(1)}$ first compared lattice parameters of the retained austenites in $\mathrm{Fe}-\mathrm{C}$ alloys at room temperature with those of the equilibrium austenites. The latter were extrapolated from high temperature values before the martensitic transformations occurred. They pointed out from the comparison that the former were smaller than the latter and the amount of reduction increased with decrease in carbon content. On the other hand, Golovchiner ${ }^{(2)}$ examined the austenite lattice parameters in $\mathrm{Fe}-\mathrm{Ni}-\mathrm{C}$ and carbon-free $\mathrm{Fe}-\mathrm{Ni}$ alloys as a function of martensite amount as well as carbon content, and he reported that the retained austenite lattice parameters were smaller than the equilibrium ones as well, but that the amount of the reduction decreased with

* Graduate School, Osaka University, Suita, Osaka 565, Japan.

** Institute of Scientific and Industrial Research, Osaka University, Yamadakami, Suita, Osaka 565, Japan. decrease in carbon content, in disagreement with the result by Ridley et al. There has not been examined such a change in austenite lattice parameters for $\mathrm{Fe}-\mathrm{Mn}-\mathrm{C}$ alloys.

As for the $\mathrm{Fe}-\mathrm{Mn}-\mathrm{C}$ alloys, there are two interesting problems on a change in martensite lattice parameters. Lyssak et al. ${ }^{(3) \sim(6)}$ found from the X-ray diffraction studies of $\mathrm{Fe}-\mathrm{Mn}$ $\mathrm{C}$ and $\mathrm{Fe}-\mathrm{Re}-\mathrm{C}$ alloys that the $c / a$ ratios of martensites measured at liquid nitrogen temperature were anomalously smaller than the normal one measured at room temperature. Alshevskiy nd Kurdjumov ${ }^{(7)(8)}$ confirmed the appearance of such an anomaly in martensite tetragonality by using $\mathrm{Fe}-\mathrm{Mn}-\mathrm{C}$ alloys. Lyssak et al. attributed the anomalous tetragonality to an occupancy of carbon atoms. That is, they suggested that a half of carbon atoms occupy the octahedral site as usual and another half the tetrahedral site, and proposed a new mechanism of the austenite to martensite transformations in $\mathrm{Fe}-\mathrm{Mn}-\mathrm{C}$ and $\mathrm{Fe}-\mathrm{Re}-\mathrm{C}$ alloys. According to the mechanism, the anomalous martensites with smaller tetragonalities were formed via a $18 \mathrm{R}$ and a $2 \mathrm{H}$ intermediate structures ${ }^{(9)}$. Afterwards, a number of studies have been made on the carbon atom sites in martensites with 
anomalous tetragonalities by means of neutron diffraction $^{(10)(11)}$ and Mössbauer spectroscopy ${ }^{(12)(13)}$ studies. However, there is a controvercy still as to whether a part of carbon atoms are at the tetrahedral site or all of them at the octahedral site.

Secondly, Nishiyama ${ }^{(14)}$, Kurdjumov et $a l .{ }^{(15)}$ and Lyssak et $a l . .^{(16)}$ have reported that a change in martensite lattice parameters is observed upon ageing of $\mathrm{Fe}-\mathrm{C}$ and $\mathrm{Fe}-\mathrm{Ni}-\mathrm{C}$ alloys at room temperature. However, such a change of martensite lattice parameters upon room temperature ageing has not been clarified in $\mathrm{Fe}-\mathrm{Mn}-\mathrm{C}$ alloys.

The purpose of the present study, therefore, is to investigate the three problems mentioned above, that is, a relation between austenite lattice parameters and carbon content and/or martensite amount, a temperature dependency and anomalous tetragonality of martensite lattice parameters, and an ageing effect of the martensite lattice parameters, by using the $\mathrm{Fe}$ $\mathrm{Mn}-\mathrm{C}$ alloys.

\section{Experimental Procedures}

Three kinds of $\mathrm{Fe}-\mathrm{Mn}-\mathrm{C}$ alloys were prepared by melting together electrolytic iron, high carbon ferro-manganese $(74.8 \% \mathrm{Mn}$, $6.84 \% \mathrm{C}$ ) and graphite under argon atmosphere in a high frequency furnace. The chemical compositions of these ingots are shown in Table 1 . The ingots of $14 \times 24 \times 120 \mathrm{~mm}^{3}$ size were hot-forged at $1273 \mathrm{~K}$, homogenized for $24 \mathrm{~h}$ at $1473 \mathrm{~K}$ in a silica capsule filled with argon gas, and hot-rolled into $3 \mathrm{~mm}$ thick sheets at $1073 \mathrm{~K}$. After the sheets were thinned down a little by grinding and chemical polishing, specimens of $23 \times 18 \times 2 \mathrm{~mm}^{3}$ were cut from the hot-rolled sheets, and they were austenitized at $1323 \mathrm{~K}$ for $1 \mathrm{~h}$ in silica capsules filled with argon gas followed by quenching

Table 1 Chemical compositions of the alloys used.

\begin{tabular}{|c|c|c|c|c|c|c|}
\hline & \multicolumn{2}{|c|}{ Top side } & \multicolumn{2}{|c|}{ Bottom side } & \multicolumn{2}{|c|}{ Mean } \\
\hline & $\% \mathrm{Mn}$ & $\% \mathrm{C}$ & $\% \mathrm{Mn}$ & $\% \mathrm{C}$ & $\% \mathrm{Mn}$ & $\% \mathrm{C}$ \\
\hline A & 8.6 & 0.54 & 8.7 & 0.59 & 8.7 & 0.57 \\
\hline B & 5.2 & 0.82 & 5.2 & 1.04 & 5.2 & 0.93 \\
\hline $\mathrm{C}$ & 4.1 & 1.22 & 4.0 & 1.27 & 4.1 & 1.25 \\
\hline
\end{tabular}

into water at room temperature. To remove an oxidized layer, the specimens were electropolished in a solution containing $\mathrm{H}_{3} \mathrm{PO}_{4}$ and $\mathrm{CrO}_{3}$.

Lattice parameters of the austenites and martensites were measured by using a RigakuDenki D-3F type X-ray diffractometer with Co $\mathrm{K}_{\alpha}$ radiation, which was equipped with a cooling stage. Bragg angles were determined from the peak positions of reflections, and the relative amount of martensites to austenites was measured from the integral intensity ratio of $\{110\}_{\alpha^{\prime}}$ reflection to $\{111\}_{\gamma}$ one, using the following equations ${ }^{(17)}$ :

$$
\begin{aligned}
& \frac{I_{\alpha^{\prime}}}{I_{\gamma}}=\frac{R_{\alpha^{\prime}} C_{\alpha^{\prime}}}{R_{\gamma}\left(1-C_{\alpha^{\prime}}\right)}, \\
& R=\frac{1}{V^{2}}\left(|F|^{2} P \frac{1+\cos ^{2} 2 \theta}{\sin ^{2} \theta \cos \theta}\right),
\end{aligned}
$$

where $C$ is the volume fraction of martensites, $V$ the volume of the unit lattices, $F$ the structure factor, and $P$ the multiplicity factor of the two reflections. Both the cooling and heating rates were $20 \mathrm{~K}$ per a minute, and the holding time at each temperature was $20 \mathrm{~min}$ and the temperature was kept constant within $1 \mathrm{~K}$ during the diffractometry.

\section{Experimental Results}

\section{Temperature dependency of austenite lattice parameters}

Figure 1 shows the austenite lattice parameters measured for three kinds of alloys as a function of temperature, where the filled and opened circles, triangles and squares are for cooling and heating, respectively. In an $\mathrm{Fe}-$ $8.7 \% \mathrm{Mn}-0.58 \% \mathrm{C}$ alloy cooled below $179 \mathrm{~K}$, it was difficult to accurately measure the Bragg angle of $(111)_{\gamma}$ reflection because of some broadening of the reflection and a very small amount of retained austenites, and therefore in the figure the austenite lattice parameter of the alloy were not plotted below $179 \mathrm{~K}$ and also for heating. The austenite lattice parameters of all the alloys linearly decrease with temperature before the martensitic transformations occur. However, they deviate from the linear 


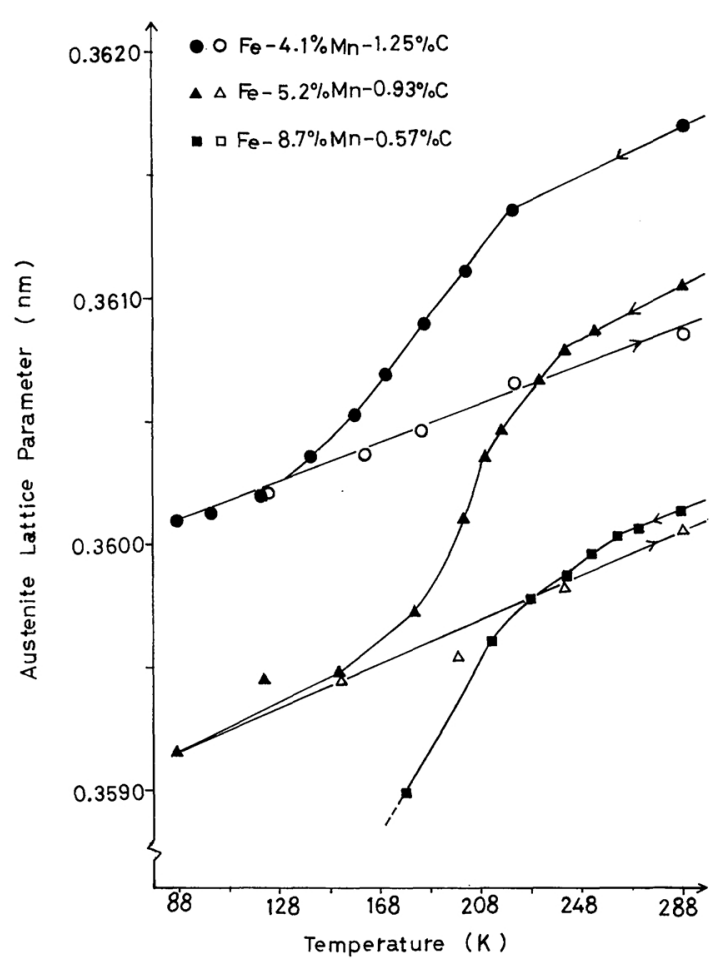

Fig. 1 Austenite lattice parameters of three Fe-Mn$\mathrm{C}$ alloys as a function of temperature, where the closed and open symbols are for cooling and heating, respectively.

relation into the reduction side after the occurrence of martensitic transformations. The amount of the reduction becomes larger with decreasing temperature and/or increasing martensite amount. The reduction rapidly appears in two alloys with 1.25 and $0.93 \% \mathrm{C}$, but it does gradually in the other alloy with $0.57 \% \mathrm{C}$. A burst phenomenon of martensite formation has been known to occur in relatively high carbon alloys as well as high alloy steels. Therefore, the rapid appearance of reduction may be attributed to such a burst formation of martensites in the former two alloys. The austenite lattice parameters of the two alloys linearly decrease with temperature after the martensitic transformations are nearly completed. When the specimens were heated up from $88 \mathrm{~K}$ to room temperature, the parameters linearly increase with temperature throughout. The temperature gradient of the linear relation upon heating is nearly the same as that of the equilibrium austenite upon cooling.
The amount of the reduction in retained austenite lattice parameters from equilibrium ones at $88 \mathrm{~K}$ is larger in the alloy with $0.93 \% \mathrm{C}$ than in the alloy with $1.25 \% \mathrm{C}$.

The retained austenite lattice parameters of the two alloys with 1.25 and $0.93 \% \mathrm{C}$ have been plotted as a function of martensite amount determined from the intensity ratio $I_{\alpha^{\prime}} / I_{\gamma^{\prime}}$ which is shown in Fig. 2. The curves denoted by 1 and $1^{\prime}$ represent the corresponding equilibrium austenite lattice parameters which were extrapolated from high temperature values before the martensitic transfomations. The amount of martensites is not linear with temperature, and so curves 1 and $1^{\prime}$ are now not linear with martensite amount although they are linear with temperature. The retained austenite lattice parameters are reduced from the equilibrium austenite ones as well, and the amount of the

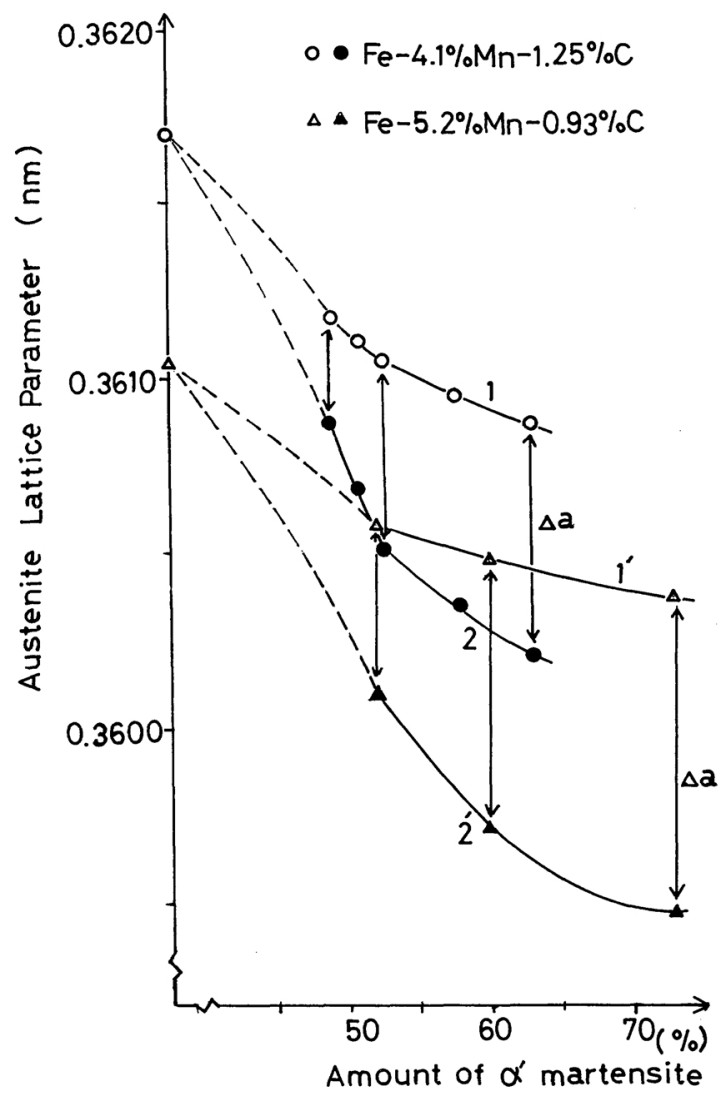

Fig. 2. Retained austenite lattice parameters of two alloys with 1.25 and $0.93 \% \mathrm{C}$, which are plotted as a function of martensite amount. 
reduction gradually increase with martensite amount but rapidly increase when the amount exceeds about $50 \%$. This is more clearly seen in Fig. 3 where the amount of reduction, $\Delta a$, has been plotted as a function of martensite amount for the two alloys. It is clear in Figs. 2 and 3 that the $\Delta a$ is larger in the $0.93 \% \mathrm{C}$ alloy than in the $1.25 \% \mathrm{C}$ alloy in the range of more than about $50 \%$ martensite, but that the $\Delta a$ is nearly the same for the two alloys in the range of less than $50 \%$ martensite. In the range more than $50 \%$, the relative reduction, $\Delta a / a$, has been plotted as a function of carbon content fixing the amount of martensite to be 50 and $60 \%$, as shown in Fig. 4. This figure indicates that the $\Delta a / a$ is larger in the $0.93 \% \mathrm{C}$ alloy than in the $1.25 \% \mathrm{C}$ alloy, and moreover that the larger the amount of martensite the steeper the slope of the $\Delta a / a$ to the carbon content abscissa. This result is opposite to that reported by Golovchiner ${ }^{(2)}$ for $\mathrm{Fe}-\mathrm{Ni}-\mathrm{C}$ alloys, and is rather similar to that reported by Ridley et al. ${ }^{(1)}$ for $\mathrm{Fe}-\mathrm{C}$ alloys. However, the present result is slightly different from that by Ridley et al. That is, they reported that $\Delta a$ increased with decreasing carbon content, not taking into consideration some effect of martensite amount. In the present case, the $\Delta a$ of two alloys with different carbon contents are nearly the same when martensite amount is less than about $50 \%$, but they depend on both the carbon content and

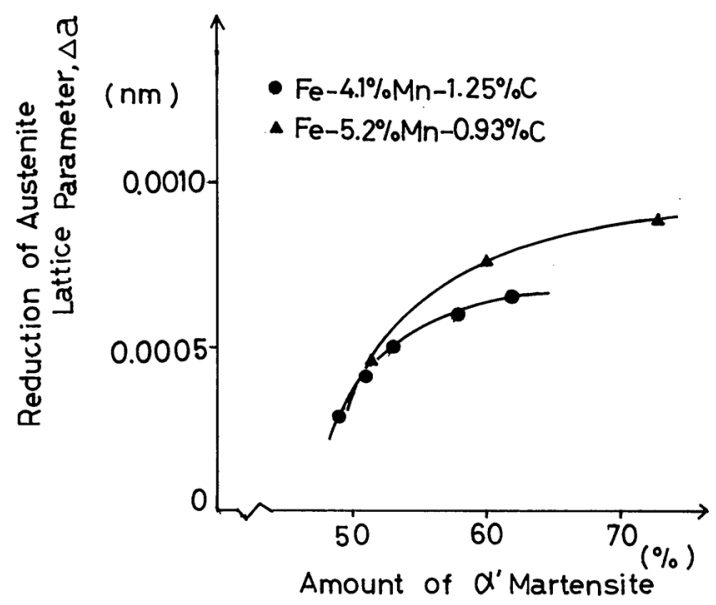

Fig. 3 Amount of reduction, $\Delta a$, as a function of martensite amount in two alloys with 1.25 and $0.93 \% \mathrm{C}$.

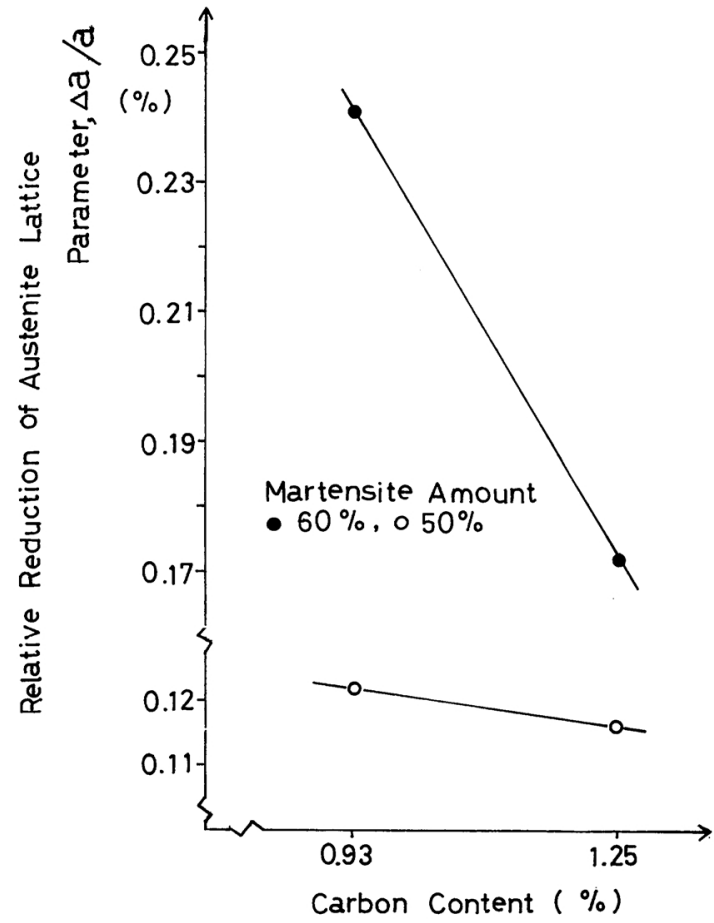

Fig. 4 Relative reduction, $\Delta a / a$, as a function of carbon content when the martensite amount is fixed to 50 and $60 \%$.

the martensite amount in the range more than $50 \%$.

\section{Temperature dependency of martensite lattice parameters}

Figure 5(a) and (b) show $a$ and $c$ parameters of the martensite lattices, respectively, in two kinds of alloys, $\mathrm{Fe}-5.2 \% \mathrm{Mn}-0.93 \% \mathrm{C}$ and $\mathrm{Fe}-4.1 \% \mathrm{Mn}-1.25 \% \mathrm{C}$, as a function of temperature. The $a$ parameters in both of the alloys decrease with temperature upon cooling to $88 \mathrm{~K}$, as indicated with filled triangles and circles for the two alloys, respectively. During heating to room temperature, the $a$ parameters increase with temperature in the beginning but linearly decrease in the range above about 170 and $150 \mathrm{~K}$ for the two alloys, as indicated with opened triangles and circles, respectively. The decrease of $a$ parameters upon cooling may be due to the usual thermal contraction and a compression effect from the surrounding austenites, and the linear decrease upon heating may be due to a carbon atom ordering 

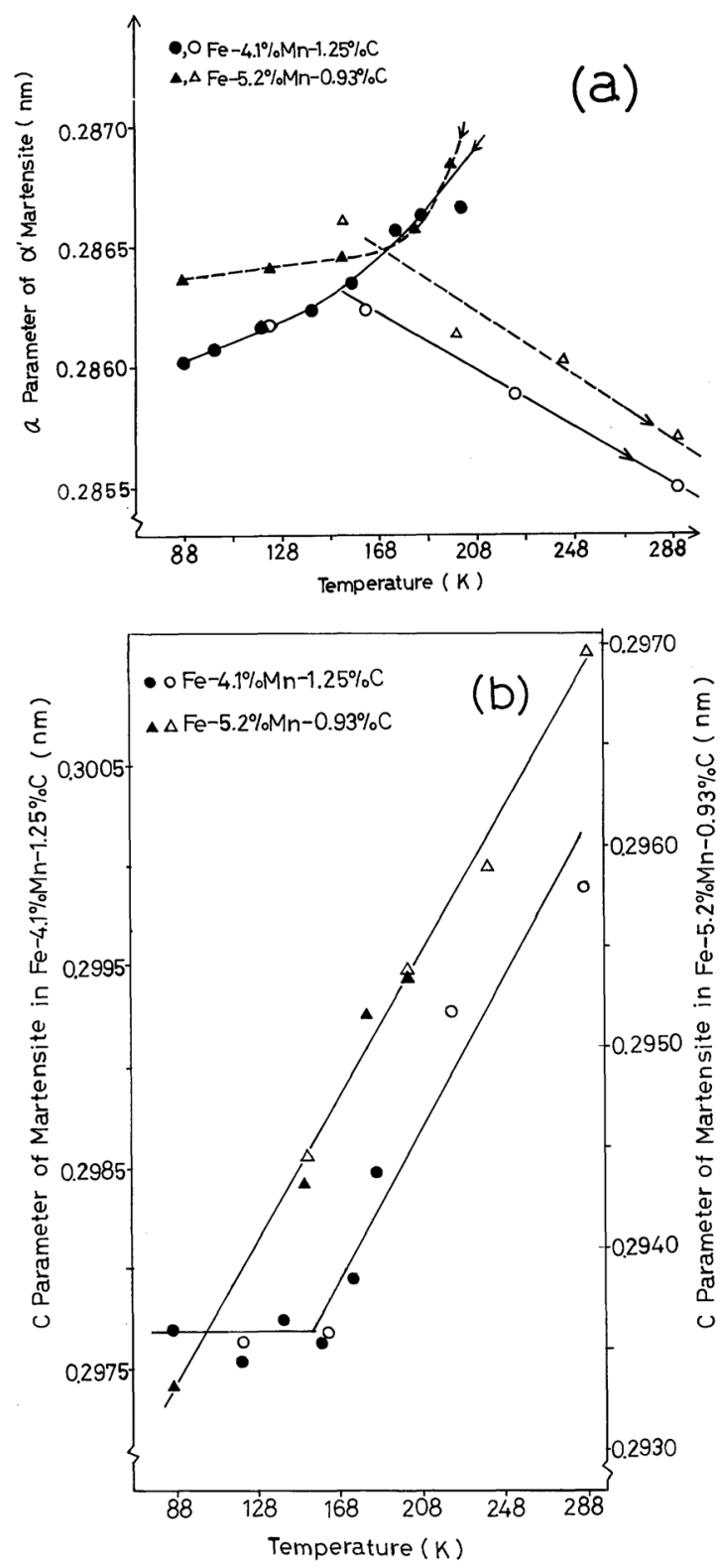

Fig. $5 a$, (a), and $c$, (b), parameters of martensite lattices in two alloys with 1.25 and $0.93 \% \mathrm{C}$, which has been plotted as a function of temperature.

into the octahedral site along the $[001]_{\alpha}$ axis. The temperatures where the $a$ parameters begin to decrease upon heating are consistent with those obtained by Koval et al. ${ }^{(18)}$ and Lyssak et $a .^{(19)}$. The former workers measured electrical resistivity changes of $\mathrm{Fe}-4.5 \sim$ $7.5 \% \mathrm{Mn}-0.6 \sim 0.75 \% \mathrm{C}$ alloys with martensites of anomalously small $c / a$ ratios, and indicated that a carbon atom ordering in the martensites occurred at $173 \mathrm{~K}$. The latter workers also measured electrical resistivity changes of an $\mathrm{Fe}-4.0 \% \mathrm{Mn}-1.4 \% \mathrm{C}$ alloy, and reported that a change of electrical resistivity due to the $\kappa^{\prime} \rightarrow \alpha_{m}$ transformation was detected at $123 \mathrm{~K}$. Carbon contents of the present alloys lie between those of the previous two measurements, and therefore it is reasonable that the beginning temperatures of carbon atom ordering for the present two alloys were 170 and $150 \mathrm{~K}$, respectively.

The changes of $c$ parameters upon cooling and heating are approximately on the same line with respect to temperature, as seen in Fig. 5(b), but they are slightly different between the two alloys. $c$ parameters in $\mathrm{Fe}-5.2 \% \mathrm{Mn}-$ $0.93 \% \mathrm{C}$ alloy linearly change all over the tested temperatures, while those in $\mathrm{Fe}-$ $4.1 \% \mathrm{Mn}-1.25 \% \mathrm{C}$ alloy are constant at temperatures below about $160 \mathrm{~K}$. The reason is not clear now for such a difference between the two alloys. Any way, the temperature dependency of $c$ parameters upon cooling and heating is larger than that of $a$ parameters upon cooling for both alloys except for the constant region for the latter alloy, indicating a stronger temperature dependency of $c$ parameters than $a$ parameters. Using the $a$ and $c$ parameters obtained, primitive unit cell volumes of the martensites have been plotted for the two alloys as a function of temperature, as shown in Fig. 6. In both the alloys, the unit cell volumes of martensites upon cooling are larger than those upon heating in the temperature region above $160 \mathrm{~K}$. This corresponds to the fact that carbon atom ordering is initiated at about $160 \mathrm{~K}$ showing a linear decrease of $a$ parameters of martensites upon heating. This means that the reduction in martensite unit cell volumes upon heating is mainly caused by the reduction in $a$ parameters but not $c$ parameters of martensites. Primitive unit cell volumes of austenites have also been plotted as a function of temperature, as shown in Fig. 7. The changes in the austenite unit cell volumes upon cooling and heating are well corresponding to those in the martensite unit cell volumes, indicating some correlation between them.

Next, the $a$ and $c$ parameters and $c / a$ ratios 


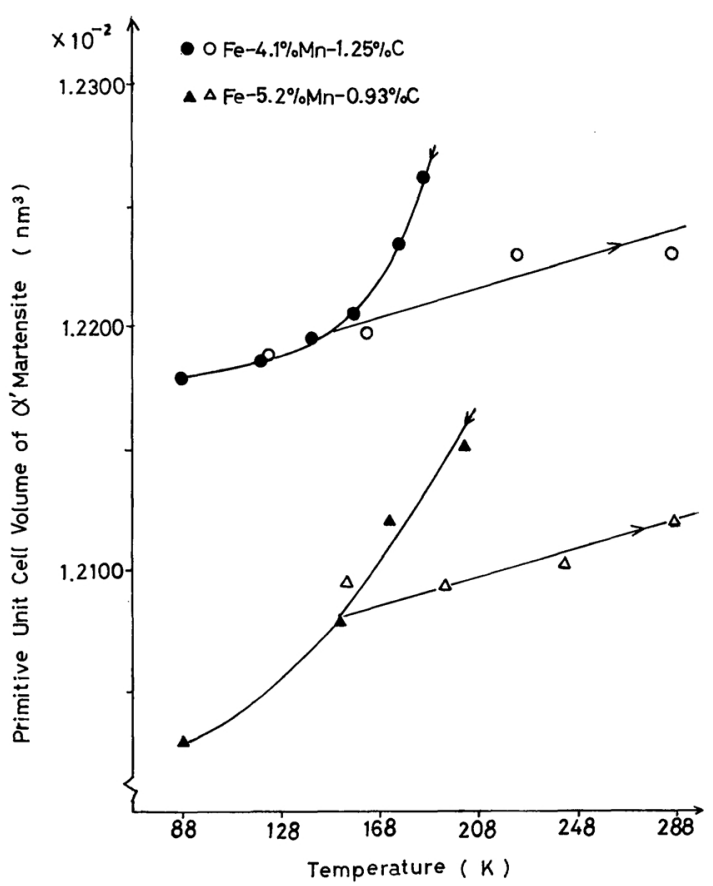

Fig. 6 Primitive unit cell volumes of martensites in two alloys with 1.25 and $0.93 \% \mathrm{C}$, which have been plotted as a function of temperature.

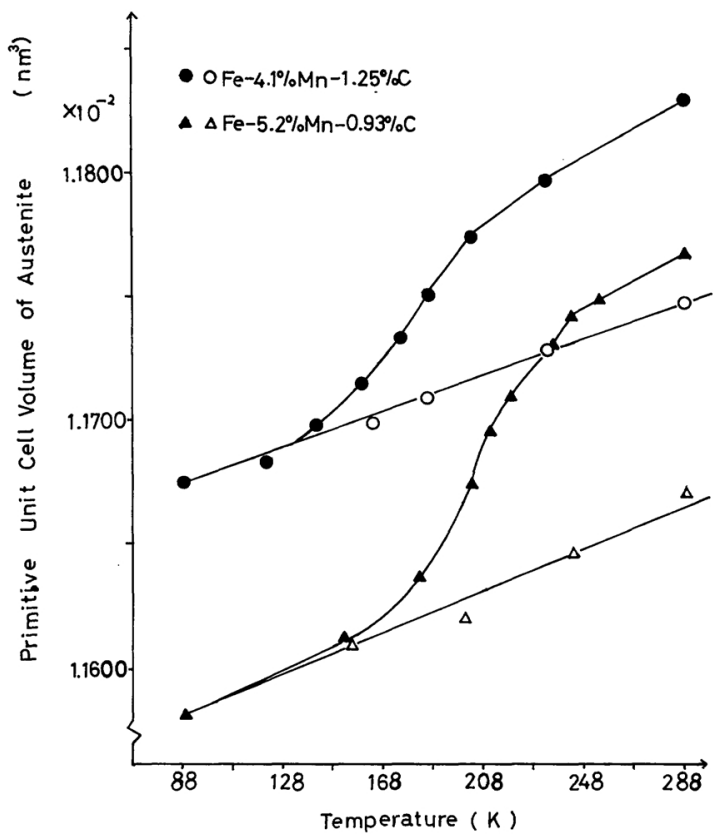

Fig. 7 Primitive unit cell volumes of austenites plotted as a function of temperature for the two alloys. of martensites at $88 \mathrm{~K}$ and room temperature have been plotted as a function of carbon content, which is shown in Fig. 8. This clearly indicates that the $c / a$ ratios are larger in alloys with higher carbon content, and that the $c / a$ ratio at $88 \mathrm{~K}$ is smaller than that after heated up to room temperature, being consistent with the results reported by Russian workers ${ }^{(3) \sim(8)}$.

\section{Room temperature ageing effects on mar- tensite lattice parameters}

Figure 9 shows the $\mathrm{X}$-ray diffractometer profiles taken from an $\mathrm{Fe}-4.1 \% \mathrm{Mn}-1.25 \% \mathrm{C}$ alloy, and there are seen $\{011\}_{\alpha^{\prime}},\{110\}_{\alpha^{\prime}}$ and $\{111\}_{\gamma}$ reflections. (a) was taken at $88 \mathrm{~K}$ immediately after the specimen was cooled to its temperature, and (b) and (c) were taken at

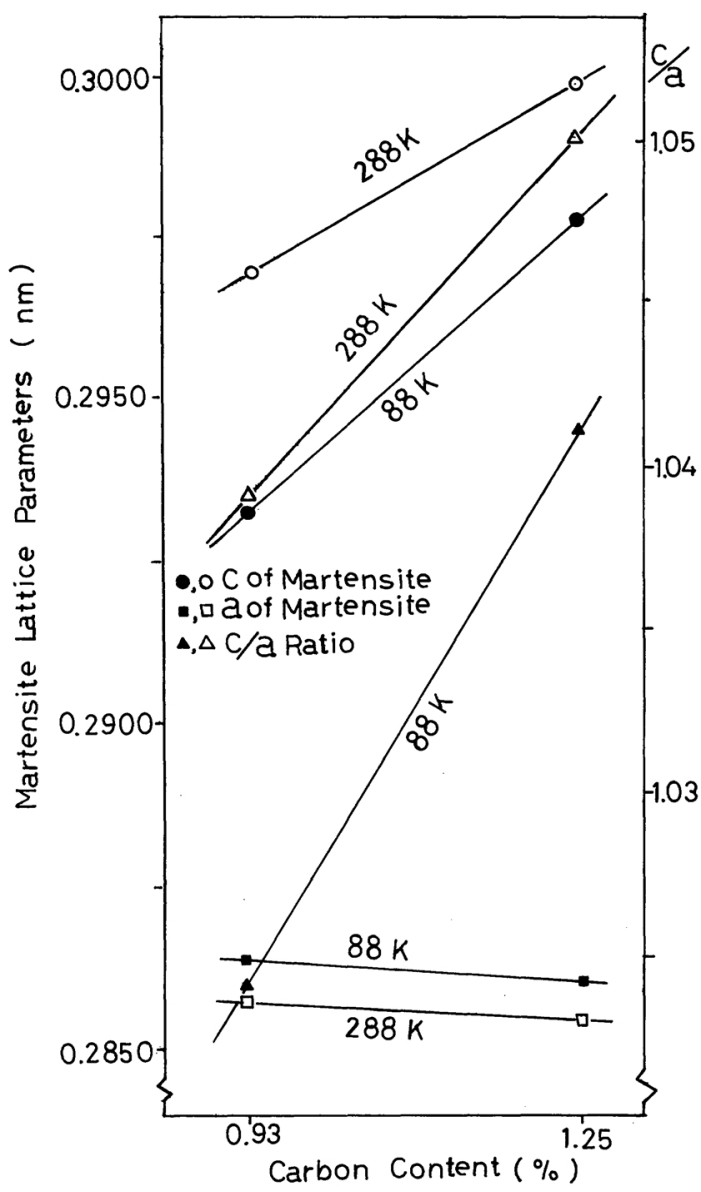

Fig. $8 a$ and $c$ parameters and $c / a$ ratios of martensites at $88 \mathrm{~K}$ and $288 \mathrm{~K}$, which are plotted as a function of carbon content. 


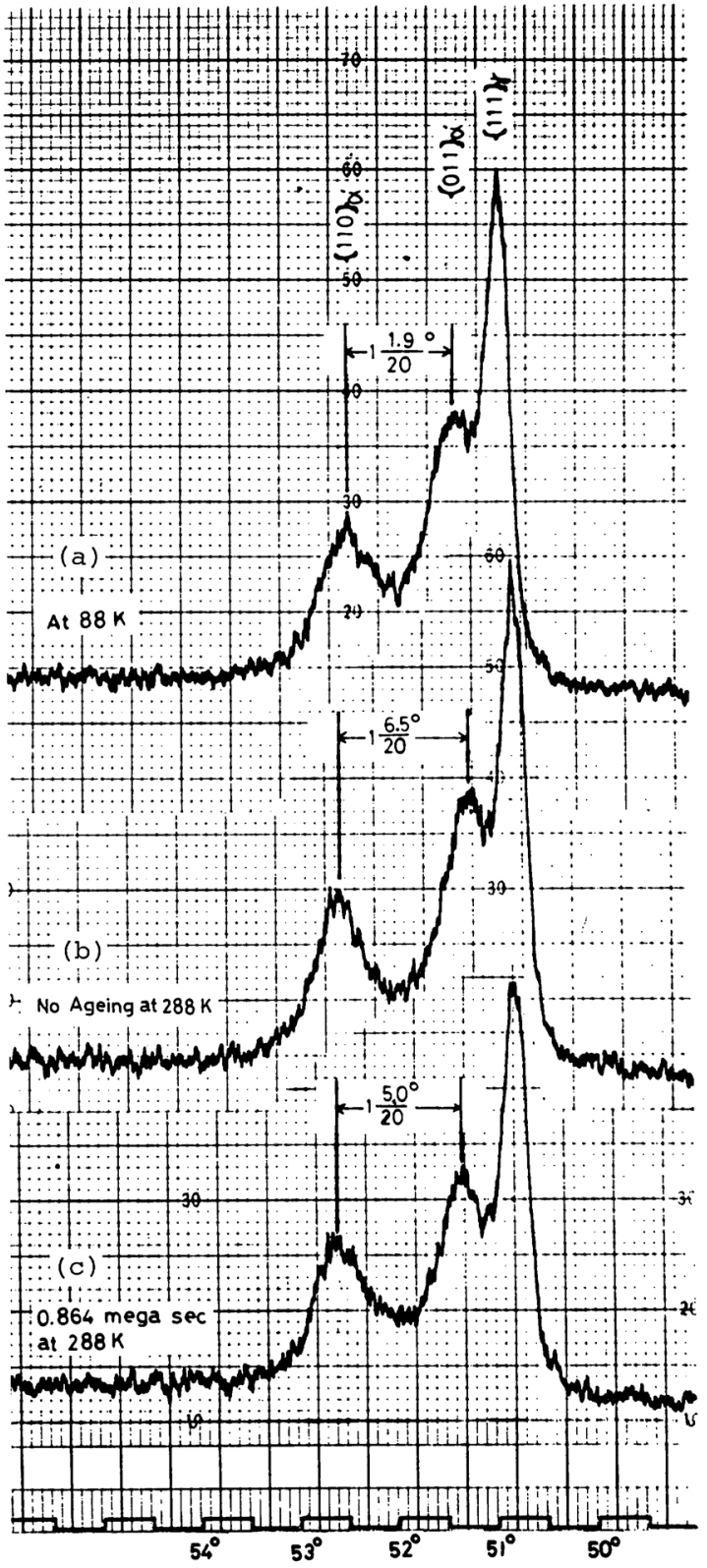

Fig. 9 X-ray diffractometer profiles taken from an $\mathrm{Fe}-4.1 \% \mathrm{Mn}-1.25 \% \mathrm{C}(\mathrm{wt} \%$ ) alloy at $88 \mathrm{~K}$, (a), and at room temperature without ageing, (b), and after ageing for $10 \mathrm{~d},(\mathrm{c})$.

room temperature without any ageing and with $10 \mathrm{~d}$ ageing, respectively, after the specimen was heated up to room temperature. The distance between the $\{011\}_{\alpha^{\prime}}$ and $\{110\}_{\alpha^{\prime}}$ peaks clearly changes in every figure. Using the profiles, lattice parameters have been deter- mined for both the martensite and austenite and they are plotted in Fig. 10 as a function of ageing time at room temperature, together with those for another $\mathrm{Fe}-5.2 \% \mathrm{Mn}-0.93 \% \mathrm{C}$ alloy. The $a$ parameters of both the martensite and austenite do not show any change even after $30 \mathrm{~d}$ ageing, this result being not consistent with a report by Kurdjumov et al. ${ }^{(15)}$ that $a$ parameters of $\mathrm{Fe}-\mathrm{Ni}-\mathrm{C}$ martensites increase with ageing time. On the other hand, the $c$ parameters of martensites rapidly decrease after $10 \mathrm{~d}$ ageing and gradually do thereafter. If the change in $c$ parameters were due to a carbon atom ordering, it would be an increase as observed when martensites were heated up from $88 \mathrm{~K}$ to room temperature. Therefore, the decrease in $c$ parameters can be considered to be due

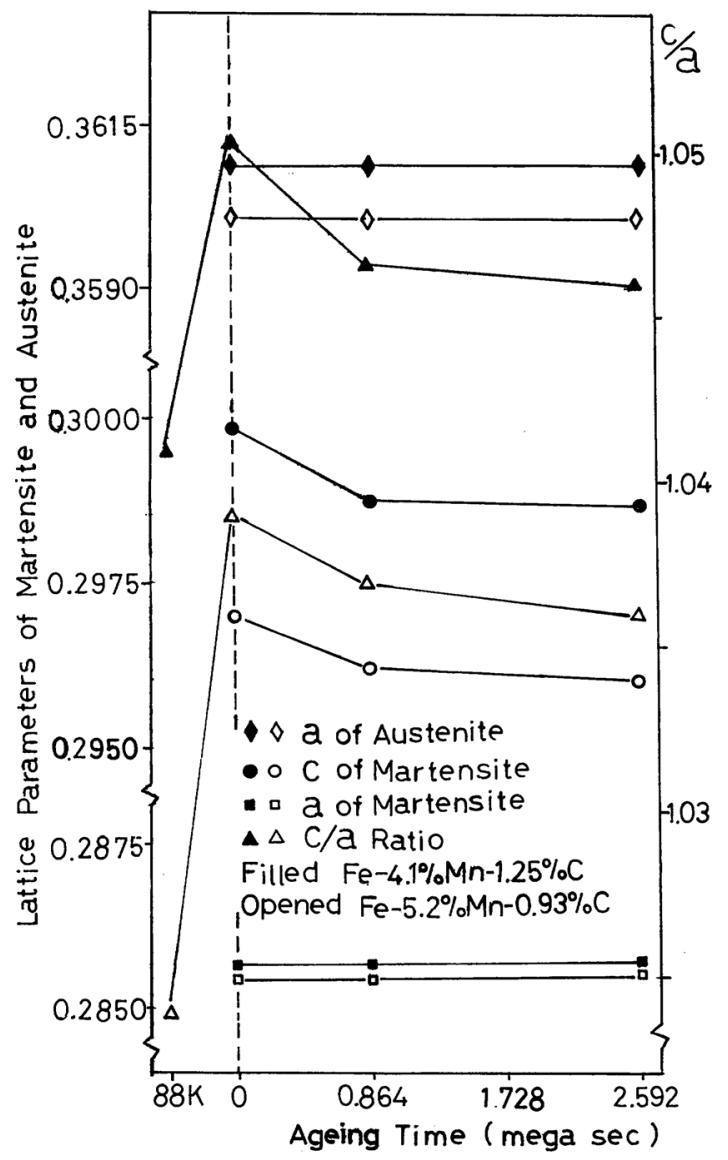

Fig. 10 Lattice parameters of austenites and martensites in two alloys with 1.25 and $0.93 \% \mathrm{C}$, which are plotted as a function of ageing time at room temperature. 
to another kind of carbon atom rearrangement such as a carbon segregation or a superlattice formation. Accompaning with the decrease in $c$ parameters, the $c / a$ ratios also decrease with increasing ageing time, as shown in the figure.

\section{Discussion}

\section{Change of austenite lattice parameters during martensitic transformations}

It has been shown in the above that retained austenite lattice parameters are rapidly reduced from the equilibrium austenite ones with progress of martensitic transfomrations. This reduction can be attributed to a stress effect caused by the volume changes during martensitic transformations besides the usual thermal contraction. Therefore, it is expected that the larger the volume change the stronger the compressive stress to the surrounding austenites. The volume change has been known to be larger in higher carbon content alloys. Therefore, the compressive stress to the surrounding austenites may be higher, and thus the reduction in retained austenite lattice parameters may be more large in higher carbon alloys. However, the reduction in $0.93 \% \mathrm{C}$ alloy is larger than that in $1.25 \% \mathrm{C}$ alloy. This means that the reduction may depend not only on the degree of the compressive stress but also on another factor. The other factor can be supposed to be the strength or compressibility of austenite lattice against to the compressive stress. The austenite strength is known to be higher in $1.25 \% \mathrm{C}$ alloy than in $0.93 \% \mathrm{C}$ alloy, and therefore the austenite lattice in the former alloy may not so compressed as in the latter alloy even if the compressive stress is higher.

In an $\mathrm{Fe}-8.7 \% \mathrm{Mn}-0.57 \% \mathrm{C}$ alloy, such a reduction in retained austenite lattice parameters has similarly been observed, as shown in Fig. 1, but could not quantitatively be analysed because of some broadening of austenite reflections and a very small amount of retained austenites. In this alloy, $\varepsilon^{\prime}$ martensites are formed besides $\alpha^{\prime}$ martensites, and therefore more complex phenomena can be supposed to occur as to the compressive stress to the surrounding austenites. Because the sense of volume change due to the $\gamma \rightarrow \varepsilon^{\prime}$ transformation is opposite to that of the $\gamma \rightarrow \alpha^{\prime}$ transformation.

\section{Changes of martensite lattice parameters during transformation and room tempera- ture ageing}

It has been shown that $a$ parameters of martensites are largely different between cooling and heating while the $c$ parameters are nearly the same upon cooling and heating. The large difference in $a$ parameters may come from the anomalous decrease in $a$ parameters upon heating. The anomalous decrease beyond the one expected from a compression effect can be attributed to a carbon atom ordering from the tetrahedral site to the octahedral site along the $[001]_{\alpha^{\prime}}$ axis. On the other hand, such a carbon atom ordering may bring about an increase in $c$ parameters as well. However, as seen in Fig. 5(b), the $c$ parameters upon heating is nearly the same as those upon cooling. This discrepancy can be explained as follows; The $c$ parameters may also be subjected to some reduction due to a compression from the surrounding austenites, and the amount of the reduction is larger upon heating than upon cooling, as is apparent from the fact (Fig. 1) that the austenite lattice parameters are more largely reduced upon heating than upon cooling when compared at the same temperature. Therefore, a part of the larger reduction upon heating might cancel with an increase due to the carbon atom ordering upon heating, and thus the $c$ parameters might be nearly the same upon cooling and heating.

As shown in Figs. 6 and 7, the changes in martensite unit cell volume upon cooling and heating are well corresponding to those in of austenite unit volume. This means that martensites are also similarly subjected to some compression from the surrounding austenites which have been compressed due to the volume changes during martensitic transformations, as known from Fig. 5(a). The amount of the compression to austenites is larger upon heating than upon cooling because of a larger amount of the martensites already formed. Therefore, the martensites may be subjected to a larger 
compressive stress from the surrounding austenites upon heating than upon cooling. This may be a possible reason why a carbon atom ordering has not been observed upon cooling but observed upon heating in the same temperature range above about $160 \mathrm{~K}$. In other words, it can be said that the carbon atom ordering is promoted by an internal compressive stress of martensites.

Lyssak and Artemyuk ${ }^{(16)}$ have reported that the martensites $\left(\kappa^{\prime}\right)$ formed at liquid nitrogen temperature decompose to two phases with a very small $(\kappa)$ and a large $\left(\alpha_{m}\right)$ tetragonalities upon heating to room temperature, although they have identified the $\kappa^{\prime}$ and $\alpha_{m}$ as bodycentered orthorhombic structures. The reduction in $c$ parameters of martensites found upon ageing at room temperature may correspond to such a decomposition to two phases. However, in the present case, reduction has been detected only for the $c$ parameters but not for $a$ parameters. Therefore, as mentioned before, it can be considered for the reduction in only $c$ parameters that carbon atoms might move from the octahedral site along the $[001]_{\alpha^{\prime}}$ axis to planar faults or dislocations of martensites to make a simple segregation as proposed by Suzuki $^{(20)}$ and Cottrell ${ }^{(21)}$, or that carbon atoms might move from the octahedral site to another site to make a superlattice as found by Nagakura et al. ${ }^{(2)}$

\section{Acknowledgement}

The present investigation was supported in part by the Grant-in-Aid for Fundamental Scientific Research (Shiken, 1978, 79) from the Ministry of Education of Japan.

\section{REFERENCES}

(1) N. Ridley, H. Stuart and L. Zwell: Trans. Met.
Soc. AIME, 245 (1969), 1834.

(2) K. Ya. Golovchiner: Fiz. metal. metalloved., 37 (1974), 363.

(3) L. I. Lyssak, Ya. N. Vovk: Fiz. metal. metalloved., 20 (1965), 540.

(4) L. I. Lyssak, Yu. N. Polishchuk and Ya. N. Vovk: Fiz. metal. metalloved., 22 (1966), 276.

(5) L. I. Lyssak and L. O. Andrushchik: Fiz. metal. metalloved., 26 (1968), 380.

(6) L. I. Lyssak and L. O. Andruchchik: Fiz. metal. metalloved., 28 (1969), 348.

(7) Yu. L. Alshevskiy and G. V. Kurdjumov: Fiz. metal. metalloved., 25 (1968), 172.

(8) Yu. L. Alshevskiy: Fiz. metal. metalloved., 27 (1969), 716.

(9) L. I. Lyssak and B. I. Nikolin: Fiz. metal. metalloved., 22 (1966), 730.

(10) I. R. Entin, V. A. Somenkov and S. Sh. Shilstein: Dokl. Akad. Nauk USSR, 266 (1972), 1096.

(11) R. Oshima, A. Kajikawa, F. E. Fujita and M. Hirabayashi: Jpn. Inst. Metals, Spring Meeting (1979), Collected abstract p. 45.

(12) H. Ino, T. Moriya, F. E. Fujita and Y. Maeda: J. Phys. Soc. Japan, 22 (1967), 346.

(13) C. Shiga, M. Kimura and F. E. Fujita: J. Japan Inst. Metals, 38 (1974), 1037.

(14) Z. Nishiyama: Kinzoku no Kenkyu (in Japanese), 11 (1934), 57.

(15) G. V. Kurdjumov and L. K. Mikhaylova: Fiz. metal. metalloved., 22 (1966), 941.

(16) L. I. Lyssak and S. A. Artemyuk: Fiz. metal. metalloved., 28 (1969), 1125.

(17) B. D. Cullity: Elements of X-ray Diffraction, Addison-Wesley Publ. Comp., Massachusetts, (1956), p. 388.

(18) Yu. N. Koval, P. V. Titov and L. G. Khandros: Fiz. metal. metalloved., 23 (1969), 52.

(19) L. I. Lyssak, L. O. Andruchchik and Yu. M. Polishchuk: Fiz. metal. metalloved., 27 (1969), 827.

(20) H. Suzuki: Sci. Rep. RITU, A4 (1952), 455.

(21) A. H. Cottrell: Strength of Solids, Phys. Soc., London, (1948), p. 30.

(22) S. Nagakura and M. Toyoshima: Trans. JIM, 20 (1979), 100. 